\title{
XX aniversario de los mártires de la UCA
}

Este mes de noviembre se celebra el XX aniversario de los mártires de la UCA, y en marzo del año que viene se celebrará el XXX aniversario de monseñor Romero. Ambas fechas son símbolos y nos recuerdan una verdad fundamental: El Salvador tiene una larga historia de víctimas, las de la muerte lenta de la opresión y la pobreza, y las de la muerte rápida de la represión y la violencia. El Salvador es un país de víctimas y mártires.

En esta revista lo recordamos con frecuencia. Hoy nos concentramos en los mártires de la UCA Joaquín López y López, Juan Ramón Moreno, Nacho Martín-Baró, Segundo Montes, Amando López e Ignacio Ellacuría. Los llamamos los "mártires jesuánicos": vivieron, trabajaron movidos a compasión por los pobres, los defendieron de sus opresores, fueron atacados y perseguidos, se mantuvieron firmes hasta el final y murieron como Jesús. Y Julia Elba y Celina, víctimas lógica y cronológicamente con anterioridad a los seis jesuitas, símbolos de centenares de millones por su dura pobreza cotidiana y por su muerte cruel. En palabras de monseñor Romero e Ignacio Ellacuría, son "el pueblo crucificado", "el siervo doliente de Yavé".

Esto es lo que recoge el primer artículo de Jon Sobrino, "Los mártires de la UCA. Exigencia y gracia", que expuso en la Universidad de Santa Clara el 5 de noviembre de 2009 - razón por la cual menciona también la visión que tenían los mártires de una universidad de inspiración cristiana-. Lo central del texto es la pregunta ¿"quién es más mártir, Ellacuría o Julia Elba"? Se puede echar mano de la analogía, pero lo más importante no es la respuesta, sino rumiar en serio la pregunta que nos remite a la pasión del mundo en todas sus formas.

Rodolfo Cardenal expone con lúcida precisión el itinerario intelectual de Ignacio Ellacuría. Clarifica el desarrollo de su pensamiento, pero también la riqueza de sus diversas dimensiones: humanista, filosófica, teológica y socio-política. Y termina con palabras breves, pero atinadas, sobre monseñor Romero, de quien quizás se puede decir que fue su compañero de batalla en la denuncia profética y en el anuncio utópico, pero "padre y maestro" en la fe. 
Alejandro Rosillo escribe sobre "El pensamiento jurídico de Ignacio Ellacuría. Hacia la construcción de una teoría crítica de derechos humanos". Presenta a Ignacio Ellacuría como maestro de la sospecha por lo que toca a la teoría de los derechos humanos y la cierta autocomplacencia en que los derechos humanos - sino son del todo respetados - sí tienen a su favor un pensamiento adecuado. Ante esto ofrece lo fundamental de la teoría de Ellacuría.

El artículo de Manuel Mazón ofrece una primicia de textos inéditos de Xavier Zubiri sobre la filosofía griega de los años treinta. Su importancia consiste en ahondar en las raíces del pensamiento zubiriano, el cual, como es sabido, tuvo un influjo decisivo en Ellacuría. El autor lo titula "Ignacio Ellacuría, 20 años después", con lo cual muestra la doble convicción de la importancia de Zubiri para Ellacuría y la importancia permanente del pensamiento de éste.

Hugo Gudiel, en su artículo "Realidad humana y religación en Zubiri y su recepción en Ellacuría", retoma el tema fundamental de la religación. Trata de responder a las preguntas ¿qué es el hombre y qué papel juega la religación en la constitución de su ser relativamente absoluto?, ¿cómo se va constituyendo la realidad del ser humano?, ¿por qué la religación es la actitud radical del hombre?

Por último, Santiago Otero escribe "Monseñor Gerardi, obispo mártir en una iglesia mártir". Con este artículo, volvemos en Revista Latinoamericana de Teología a los mártires más allá de nuestras fronteras. Ya han aparecido artículos sobre Dietrich Bonhoeffer, Cristophe Munzihirwa y Alfred Delp. Mantener viva la conciencia de la universalidad de los mártires jesuánicos y, sobre todo, del pueblo crucificado al que hay que bajar de la cruz, pertenece a la esencia de esta revista.

Lo importante de este número de la revista es aportar a mantener vivos a los mártires, pues de ellos depende en definitiva que la Iglesia siga con vida y que vivifique a los demás. Igualmente importante, y en algunos aspectos todavía más, es mantener vivo al pueblo crucificado, a los millones de Julia Elba y Celina. Es lo que pretendemos siempre y lo concentramos en los aniversarios. En este se ha dado palabra a los mártires, incluso en Casa Presidencial; en el Centro Monseñor Romero se ha inaugurado una Sala de los Mártires renovada; en este número de la revista los mantenemos vivos con el concepto y la palabra. Pero lo importante son los mártires. Que sigan vivos y vivificantes.

\section{Revista Latinoamericana de Teología}

